Brazilian Journal
of Chemical
Engineering

ISSN 0104-6632

Printed in Brazil

www.abeq.org.br/bjche

Vol. 27, No. 03, pp. 483 - 497, July - September, 2010

\title{
DEVELOPMENT OF A MICRO-HEAT EXCHANGER WITH STACKED PLATES USING LTCC TECHNOLOGY
}

\author{
E. Vásquez-Alvarez ${ }^{1}$, F. T. Degasperi ${ }^{2}$, L. G. Morita ${ }^{1}$, \\ M. R. Gongora-Rubio ${ }^{3}$ and R. Giudici ${ }^{1, *}$ \\ ${ }^{1}$ Universidade de São Paulo, Escola Politécnica, Department of Chemical Engineering, \\ Av. Prof. Luciano Gualberto 380, Trav. 3, CEP: 05508-900, São Paulo - SP, Brazil. \\ E-mail: *rgiudici@usp.br; elsa@pqi.ep.usp.br; leonardo.morita@gmail.com \\ ${ }^{2}$ Faculdade de Tecnologia de São Paulo, FATEC-SP, CEETEPS, UNESP, \\ São Paulo - SP, Brazil. E-mail: ftd@fatecsp.br \\ ${ }^{3}$ Instituto de Pesquisas Tecnológicas, CTPP, Rua Prof. Almeida Prado 532, \\ CEP: 05508-901, São Paulo - SP, Brazil. \\ E-mail: magoru@gmail.com
}

(Submitted: December 24, 2009 ; Revised: September 13 , 2010 ; Accepted: September 13, 2010)

\begin{abstract}
A green ceramic tape micro-heat exchanger was developed using Low Temperature Co-fired Ceramics technology (LTCC). The device was designed by using Computational Aided Design software and simulations were made using a Computational Fluid Dynamics package (COMSOL Multiphysics) to evaluate the homogeneity of fluid distribution in the microchannels. Four geometries were proposed and simulated in two and three dimensions to show that geometric details directly affect the distribution of velocity in the micro-heat exchanger channels. The simulation results were quite useful for the design of the microfluidic device. The micro-heat exchanger was then constructed using the LTCC technology and is composed of five thermal exchange plates in cross-flow arrangement and two connecting plates, with all plates stacked to form a device with external dimensions of $26 \times 26 \times 6 \mathrm{~mm}^{3}$.

Keywords: CFD; LTCC; Microstructured heat exchanger.
\end{abstract}

\section{INTRODUCTION}

Global competition represents a major challenge for all industries and also for research leading to the birth of new technologies and new processes. In this context, Kockmann (2008) commented that both process technology and Microsystems technology are interdisciplinary engineering branches that relate physics, chemistry, biology and engineering as enabling tools for various applications. Also, process intensification with miniaturized equipment connects many areas of knowledge. Each field of studies, from mechanical or chemical engineering and chemistry to
Microsystems engineering, has its own knowledge, methods and technology.

According to Hessel et al. (2004), process intensification is a concept aimed at notable improvements in chemical processing. The aim of intensification is to optimize capital, energy, environmental and safety benefits through radical reductions in the physical size of equipments.

The advances in Microfabrication technology have opened a new field of research in the Chemical Process area. These techniques applied to microelectronics created huge new markets and are now applied to Chemical Engineering, creating new

*To whom correspondence should be addressed

This is an extended version of the manuscript presented at the PSE 2009 -10th International Symposium on Process Systems Engineering, 2009, Salvador, Brazil, and published in Computer Aided Chemical Engineering, vol. 27, p. 1773-1778. 
horizons for extraordinary developments. Regarding this subject, Ehrfeld et al. (2000) commented that microstructures are small units of a miniaturized continuous flow system, in the majority of cases referring to channel structures. Different technologies have been preferably applied for fabrication of microdevices: bulk micromachining, dry etching processes, micromolding, wet chemical etching of glass, advanced mechanical milling and drilling, laser ablation, among others. Several of these technologies are usually combined in the microfabrication process.

Commenge et al. (2002) commented that the use of microreactors for industrial scale production requires a large number of parallel reactors, since each of them is responsible for only a small volume dedicated to the reaction.

A wide range of research has been carried out on different processes and applications. Kang and Tseng (2007), for instance, developed a theoretical model for predicting the thermal and fluidic characteristics of a cross-flow micro-heat exchanger. This model was used to validate the design of a micro-heat exchanger constructed with the MicroElectroMechanical Systems (MEMS) technology and showed viable and efficient results.

Commenge et al. (2002) evaluated the influence of the geometrical dimensions of a microstructured reactor on the velocity distribution between the channels. In order to achieve this goal, they designed a plate with parallel and rectangular channels, developed an estimated model and compared with the finite volume model.

In a microdevice with channeled plates, the homogeneity of the fluid is very important for the residence time distribution. Therefore, some authors have been employing Computational Fluid Dynamics (CFD) simulation to evaluate the flow distribution in microstructured plates.

Tonomura et al. (2004) designed a microdevice using CFD. The simulations showed that the uniformity of the flow between the microchannels greatly depends on the shape of the distribution chambers, on plate length and the shape of the fluid inlet. In another study using the same approach, Griffini and Gavriilifid (2007) observed that twodimensional (2-D) simulations may be misleading, so that microchanneled plates have to be evaluated in three dimensions (3-D); the critical values for the Reynolds number should also be analyzed.

Alm et al. (2008) evaluated the behavior of a micro-heat exchanger using CFD simulation and constructed ceramic micro-heat exchangers using stereolithography processes and low-pressure injection molding. Arzamendi et al. (2009) used CFD simulation to evaluate steam methane reforming in a microchanneled catalytic reactor. They simulated microchannel groups and assumed a thin and homogeneous catalyst layer deposited on the walls. The simulation results showed that methane conversions higher than $97 \%$ could be achieved for the steam reforming.

Among the microdevice fabrication technologies, Low Temperature Co-fired Ceramics (LTCC) have been largely used because this kind of technology enables the possibility of fabricating 3-D devices like holes, channels and hollows on a scale ranging from one micron to a few millimeters using multiple-layer green ceramics. Malecha and Golonka (2008) commented that this technology is especially interesting to build microfluidic systems such as flow sensors, micropumps, microvalves, micromixers and microreactors but, in order to build such structures, it is necessary to develop a repeatable method of microchannel construction in LTCC. The fabrication process using LTCC hybrid technology was described in general terms by Gongora-Rubio et al. (2001).

Recent researches have shown the integration of microfluidics and microelectronics using LTCC hybrid technology. Martinez-Cisneros et al. (2007) developed microflow analyzers incorporating a temperature control system based on an actuator (resistor) and a sensor (thermistor). Ibáñez-García et al. (2008) presented an overview of LTCC technology and pointed it out as an alternative for the construction of microanalyzers. Martinez-Cisneros et al. (2009) developed a microanalyzer with amperimetric detection using LTCC technology.

The general objective of the present work was the development of a micro-heat exchanger with multiplates, including the steps of the microplate design, the simulation of the flow in this device using CFD software, and the manufacturing of a green ceramic micro-heat exchanger. The device was designed by using Computational Aided Design (CAD) software and simulated in 2-D and 3-D using COMSOL Multiphysics, a CFD package to evaluate the fluid behavior in the microchannels. The construction was performed using LTCC technology. Several preliminary tests were made before the fabrication of the 3-D devices, such as: Computer Numeric Control (CNC) machining, glass ceramic tape adherence, device lamination and sintering. The micro-heat exchanger is composed of five thermal exchange plates in cross-flow and two connecting plates with $26 \times 26 \times 6 \mathrm{~mm}^{3}$. 


\section{DESIGN AND CFD SIMULATIONS}

On the whole, the CFD simulation may be divided into pre-processing, solution and postprocessing. The first phase comprises the geometry design, which may be carried out with this software or imported from another one - CAD, for instance; the creation and application of the mesh; the choice of the physical models; and the specification of the boundary conditions. The solution phase involves the configurations of the solver used by the software. The post-processing constitutes the third phase of the simulation, in which the user may choose which variables must be presented and the specific way to do it.

In this work, several different potential geometries were analyzed in order to define the construction of the device, but only four of them are discussed in this work. The geometries were simulated and the results were compared to decide the best configuration for the construction. In order to evaluate the results, graphs showing velocity and pressure curves were used. The micro-heat exchanger design presents stacked plates with parallel and rectangular shaped channels.

\section{Microplate Designs}

Several variations in the fluid distribution were studied in order to assess and determine the best fluid distribution in terms of the homogeneity of fluid flow in each of the parallel channels. Among the various options in terms of channel number, length, width and height, four geometries were projected in the CAD. Each plate has two holes: one for the passage to the next plate and another for the hollow outflow.

The main challenge of the design was the hollow region that distributes the fluid to the channels. Figure 1 shows the fluid flow in the proposed geometries. Thus, the first proposed project (A-type) has a side entrance and a triangular shaped fluid distribution hollow (see Figure 1(a)). In the second project, the B-type, the fluid inflow is in the central part of the plate and the distribution is also triangular shaped, according to Figure 1(b). In the third proposal (C-type), the fluid distribution is circular in shape, according to Figure 1(c). There is also a fourth geometry (D-type). In this case, the distribution hollow is circular in shape just like in the C-type, but this design has two walls at the edges, as shown in Figure 1(d).

The dimensions of the four proposed geometry types evaluated in the CFD simulations are shown in Table 1.

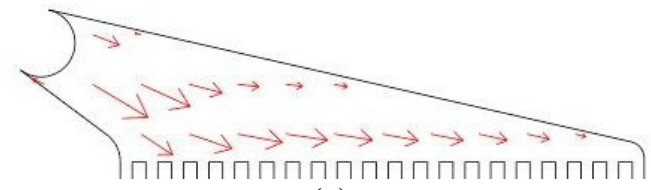

(a)

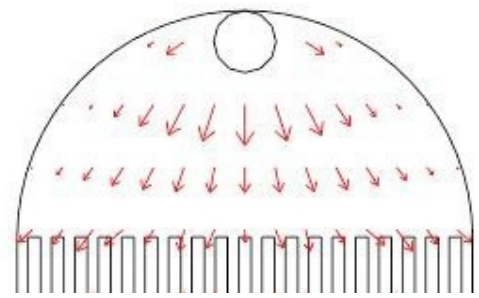

(c)

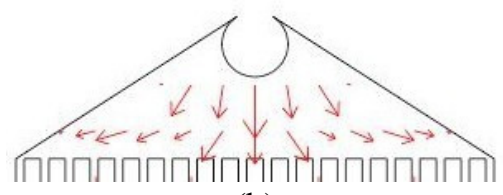

(b)

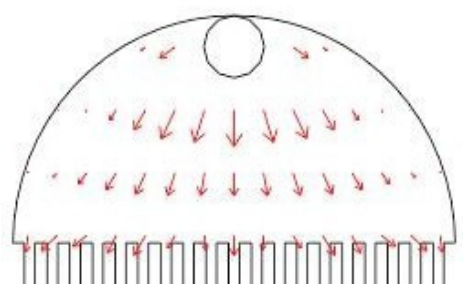

(d)

Figure 1: Fluid distribution hollows proposed for the microplate.

Table 1: Proposed plate dimensions.

\begin{tabular}{|c|c|c|c|c|c|c|}
\hline \multicolumn{3}{|c|}{ Characteristic } & \multicolumn{4}{|c|}{ Types } \\
\hline Symbol & name & unit & A & B & $\mathbf{C}$ & D \\
\hline $\begin{array}{l}\mathbf{n} \\
\mathbf{W}_{\mathbf{c}} \\
\mathbf{h} \\
\mathbf{L} \\
\mathbf{W}_{\mathbf{a}} \\
\mathbf{r h}\end{array}$ & $\begin{array}{l}\text { number of channels } \\
\text { channel width } \\
\text { channel high } \\
\text { channel length } \\
\text { channel wall width } \\
\text { hole radius }\end{array}$ & $\begin{array}{l}- \\
\mu \mathrm{m} \\
\mu \mathrm{m} \\
\mu \mathrm{m} \\
\mu \mathrm{m} \\
\mu \mathrm{m}\end{array}$ & $\begin{array}{r}21 \\
350 \\
500 \\
13000 \\
400 \\
1000\end{array}$ & $\begin{array}{r}20 \\
250 \\
500 \\
12250 \\
500 \\
1000\end{array}$ & $\begin{array}{r}20 \\
350 \\
500 \\
15677 \\
400 \\
1000\end{array}$ & $\begin{array}{r}19 \\
350 \\
500 \\
15677 \\
400 \\
1000\end{array}$ \\
\hline
\end{tabular}




\section{Model Equations}

In order to simplify the problem, some assumptions are adopted in this work. The first assumption is the incompressibility. In the second one, the fluid was considered to be continuum and, in this case, the Knudsen number (Kn) must be low $(\mathrm{K} n<0.01)$ and the Navier-Stokes equations are applicable. The Knudsen number (see Equation (1)) is defined as the molecular mean free path $(\Lambda)$ divided by the minimal characteristic of the system $\left(\mathrm{d}_{\text {min }}\right)$. The Kn is used to estimate the influence of the molecular mobility on the fluid behavior inside microstructures.

$$
\mathrm{Kn}=\frac{\Lambda}{\mathrm{d}_{\min }}
$$

The flow regimes of gases concerning rarefaction effects can be classified according to the range of the $\mathrm{Kn}$, as shown in Table 2.

\section{Table 2: Different regimes as a function of $\mathrm{Kn}$} (Kockmann, 2008).

\begin{tabular}{|l|c|}
\hline \multicolumn{1}{|c|}{ Fluid regimes } & Knudsen number \\
\hline Continuous & $\mathrm{Kn}<10^{-2}$ \\
Slip-flow regime & $10^{-2}<\mathrm{Kn}<10^{-1}$ \\
Transition flow Regime & $10^{-1}<\mathrm{Kn}<10$ \\
Free molecular flow & $\mathrm{Kn}>10$ \\
\hline
\end{tabular}

The mean free path, according to Commenge et al. (2002), is given by:

$$
\Lambda=\frac{\mathrm{RT}}{\pi \sqrt{2} \mathrm{PA} \sigma^{2}}
$$

where $\mathrm{R}$ is the universal gas constant, $\mathrm{T}$ is the system temperature; $\mathrm{P}$ is the minimum operating pressure, $\mathrm{A}$ is the Avogadro number and $\sigma$ is the molecular diameter.

The third assumption is the laminar regime; the Reynolds number (Re) should be lower than 2300 for rectangular microchannels (Kockmann, 2008).

The equation that describes the fluid flow, considered incompressible, is given by the NavierStokes equation for momentum conservation (Equation (3)) with the continuity equation for the mass conservation (Equation (4)):

$$
\begin{aligned}
& \rho \frac{\partial \mathrm{u}}{\partial \mathrm{t}}+\rho \mathrm{u} \cdot \nabla \mathrm{u}=-\nabla \mathrm{p}+\mu \nabla^{2} \mathrm{u}-\rho \mathrm{g} \\
& \nabla \cdot \mathrm{u}=0
\end{aligned}
$$

The Reynolds number is defined as:

$$
\operatorname{Re}=\frac{\rho \cdot v_{\mathrm{m}} \cdot \mathrm{D}_{\mathrm{H}}}{\mu}
$$

where $D_{H}$ is the hydraulic diameter (defined as $D_{H}=$ $4 \mathrm{~S} / \mathrm{P}_{\mathrm{w}}, \mathrm{S}$ being the cross-sectional area and $\mathrm{P}_{\mathrm{w}}$ the wet perimeter of the channel), $\mathrm{v}_{\mathrm{m}}$ is the average flow velocity in the cross section of the channel, $\rho$ is the density and $\mu$ is the dynamic viscosity.

The parameters defined in Equations (1), (2) and (5) were used to make a quantitative analysis of the simulations in the channels and assess the adequacy of the assumptions.

For simulation purposes, nitrogen at $600 \mathrm{~K}$ with 1 bar pressure, $0.561 \mathrm{~kg} / \mathrm{m}^{3}$ density, $2.95 .10^{-5}$ Pa.s viscosity (Incropera and De Witt, 2003) and fluid flow in the top-bottom direction were considered.

\section{Boundary Conditions}

The boundary conditions assumed in the simulations were:

- No fluid slipping at the walls

- Zero relative pressure in the outflow and

- Uniform inflow velocities

The specifications of these conditions regarding the fluid inflow were previously determined by qualitatively comparing the results of 2-D and 3-D simulations.

\section{Mesh Creation}

This process is necessary for the feeding of the pre-processor, in which the physical models are inserted. The specification of the mesh type, method and size is necessary for its generation by the software. This process is repeated and evaluated until the desired results are obtained. Preliminary simulations showed that the chosen meshes provided simulation results that were grid-independent. The mesh quality was evaluated by using the metrics provided by the COMSOL software, the Aspect Ratio (AR). This parameter for triangular and quadrilateral meshes is a function of the area and the side lengths, and for tetrahedral elements it is a function of the volume and the edge lengths. The Aspect ratio is a number between 0 and 1 , and the ideal value is 1 (equilateral triangles in $2 \mathrm{D}$ or regular tetrahedrons in 3D). Values larger than 0.3 and 0.1 are sufficient for triangular and tetrahedral elements, respectively (i.e., the mesh quality is acceptable) and, when the minimum element quality of the 
generated mesh is extremely poor $\left(<10^{-4}\right)$, an automatic message warns the user.

In this work, the meshes adopted for the computer simulations were triangular with normal size and a regular refinement method for the 2-D cases, as shown in Figure 2.

In the 3-D simulations, tetrahedral meshes with the longest refinement method were used, as shown in Figure 3 for a specific region in the C-type geometry.

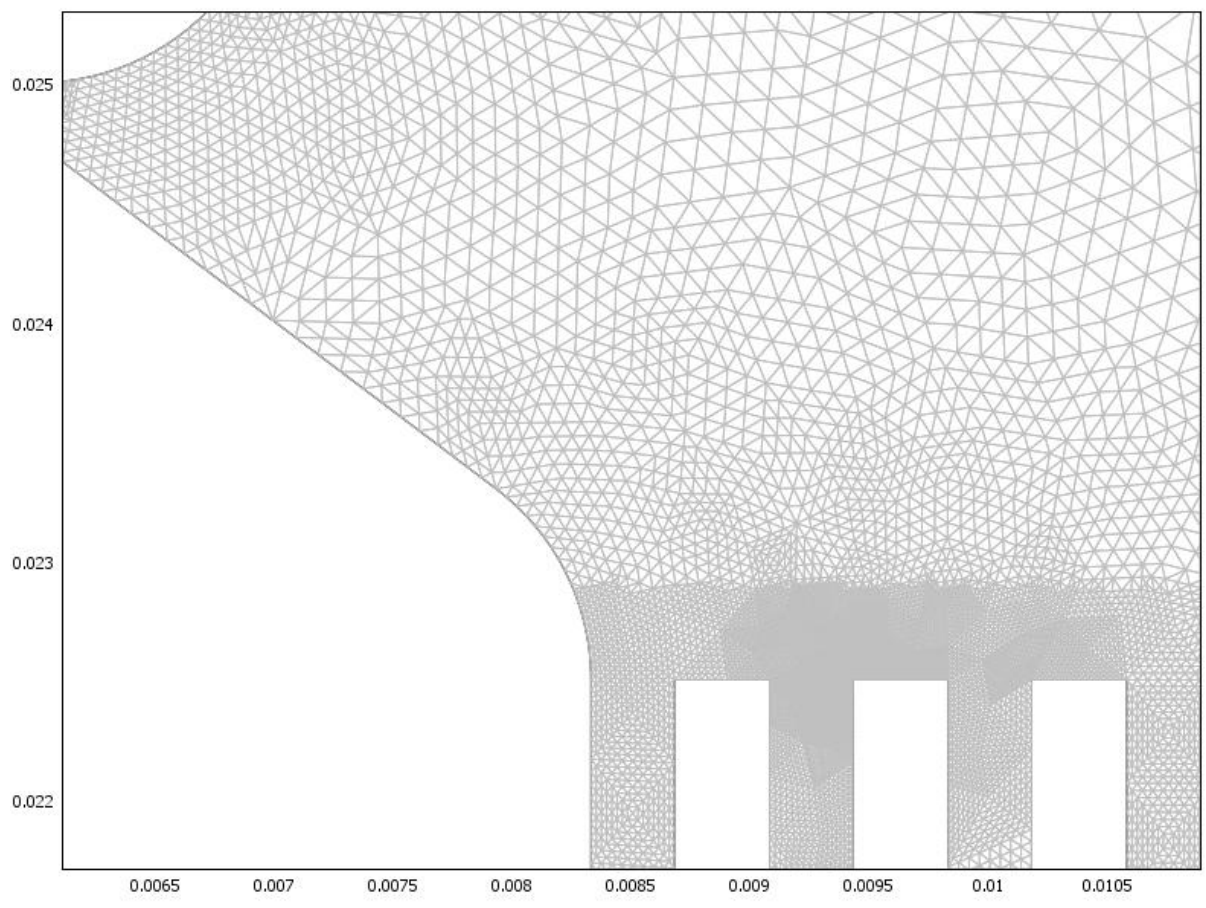

Figure 2: Triangular mesh for the A-Type geometry (2-D).

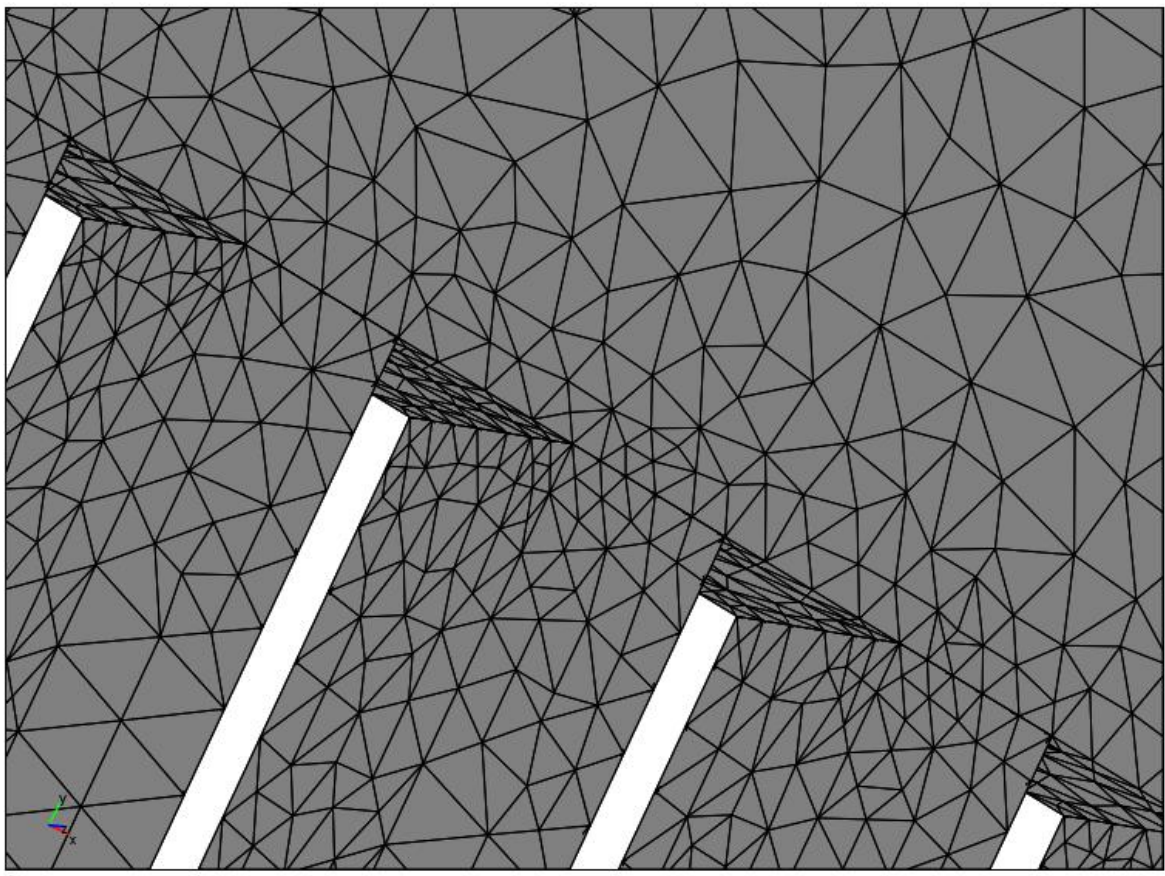

Figure 3: Tetrahedral mesh for C-Type geometry (3-D). 


\section{Fluid Behavior in CFD}

The choice of the geometry of the device plate involves fluid dynamics, so simulations of the corresponding processes are necessary to make the device design cheaper, faster, more reproducible and more controllable. In this case, a simplified CFD simulation was used to assess the effect of the chamber for fluid distribution to the channels and to determine the best fluid flow inside the channels. This simulation was made with COMSOL Multiphysics v 3.4, which is based on the finite elements method for the solution of problems involving partial differential equations on a personal computer (Intel Core 2 Duo $2.13 \mathrm{GHz}$ and 4 GB of RAM).

Once the solver is chosen, it is executed, producing a result file, which contains the variations of velocity, pressure and any other variables.

This information may lead to modifications in the design, which can be tested by modifying the CAD design and observing the resulting effects.

\section{2-D Simulations}

Four geometric projects denominated A, B, C and D types were simulated in 2-D for different velocities and these results were analyzed and compared. A quantitative analysis of the simulation results was done only for cases in 2-D, since the simulations in 3-D were too demanding for the computer, making it impossible to use a mesh with enough elements.

The quantitative analysis of the results was made at two positions along the length of each channel; the gas goes in through the superior part of the plate and comes out through the inferior part, as can be seen in Figure 4.

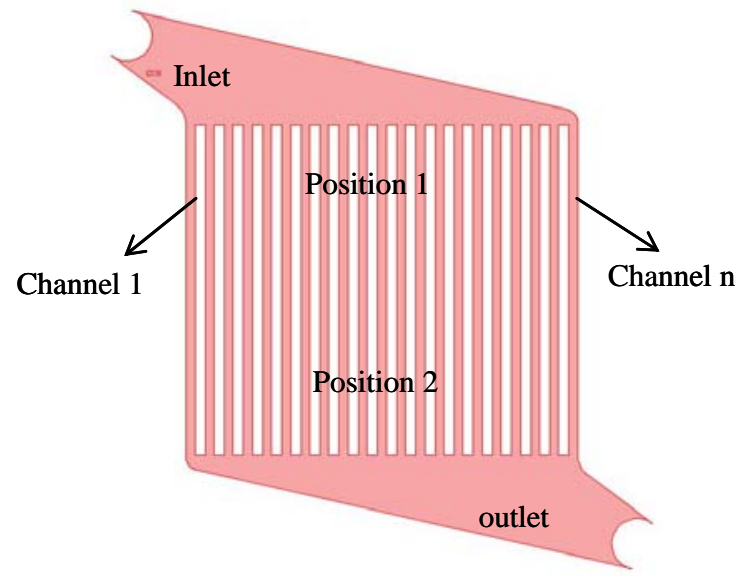

Figure 4: Nomenclature adopted in the analysis of the simulations.

\section{A-Type Geometric Project}

The first plate analyzed had triangular diagonal hollows; this geometric form was studied by Commenge et al. (2002). The geometric project was simulated using a fluid with a $10 \mathrm{~m} / \mathrm{s}$ velocity and the meshes adopted for the implementation of computer simulations were triangular.

The results confirmed the adopted hypothesis: the laminar regime $(\mathrm{Re}=20.1)$, the incompressibility of the system $(\Delta \mathrm{P}=1384)$ and $\mathrm{Kn}=0.00031(<0.01)$. For the calculation of this last parameter, the width of the channel was used as the characteristic dimension and also Equations (1) and (2). In Figure 5 , it is possible to observe the micro-heat exchanger plate simulation.

\section{B-Type Geometric Project}

The second geometric project simulated and analyzed has the fluid inlet in the central part of the plate and the dimensions are presented in Table 1. With the purpose of evaluating the behavior of the gas inside the channels, the proposed project was simulated for a velocity of $10 \mathrm{~m} / \mathrm{s}$. Note the heterogeneous behavior in the plate simulation shown in Figure 6. Finally, the adopted hypothesis was verified. $(\mathrm{Re}=28.1, \Delta \mathrm{P}=771$ and $\mathrm{Kn}=$ 0.00043).

\section{C-Type Geometric Project}

This plate presents circular hollows; the dimensions are shown in Table 1 . Similarly to the previous cases, the inlet velocity used was $10 \mathrm{~m} / \mathrm{s}$. In Figure 7, there is an illustration of the geometry and the distribution of velocities in both the channels and the hollows. It was again verified that the flow regimen is laminar $(\mathrm{Re}=44.4), \mathrm{Kn}=0.00031(<0.01)$ and the system is incompressible $(\Delta \mathrm{P}=1293)$.

\section{D-Type Geometric Project}

Bearing in mind the results of Geometry C, a small modification was proposed in this project with the extremities formed by walls instead of channels as in the previous case (C-type). The project contains 19 channels with the same dimensions as in the previous case. An illustration of this simulation is shown in Figure 8. The distribution of velocities is more homogeneous in both the channels and the hollows. 


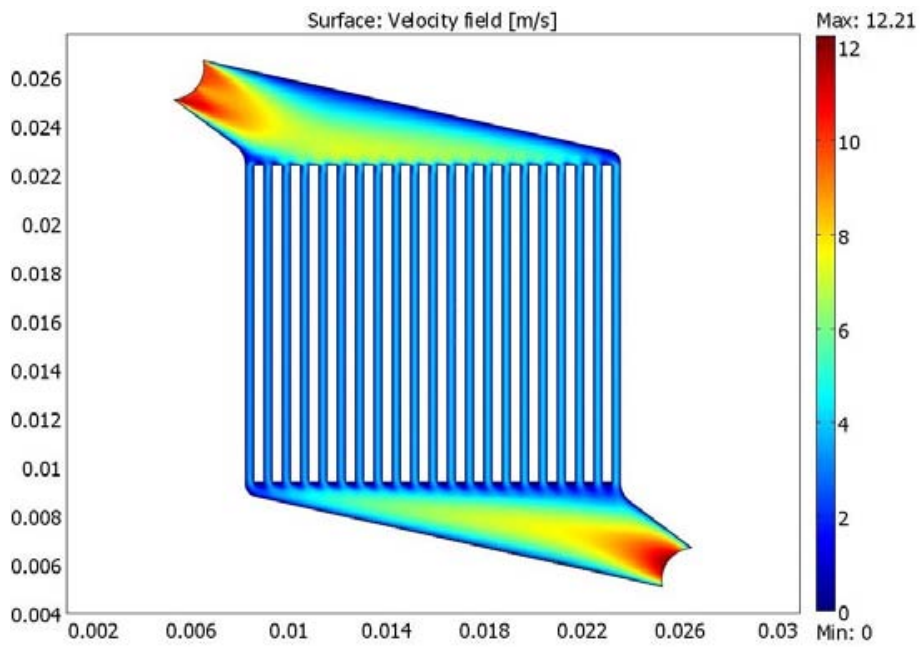

Figure 5: Flow distribution in the A-type plate.

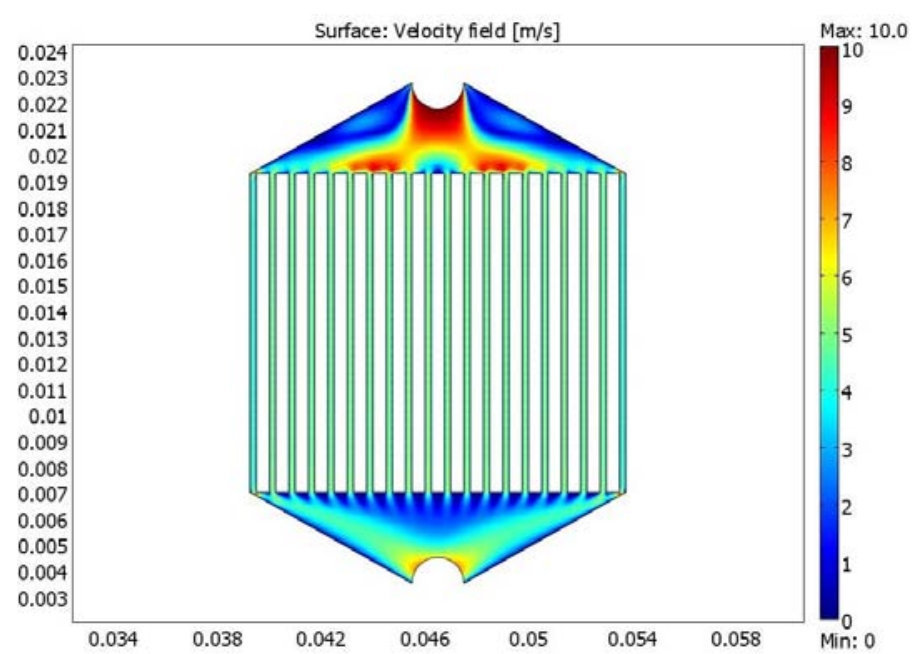

Figure 6: B-type Geometry flow distribution.

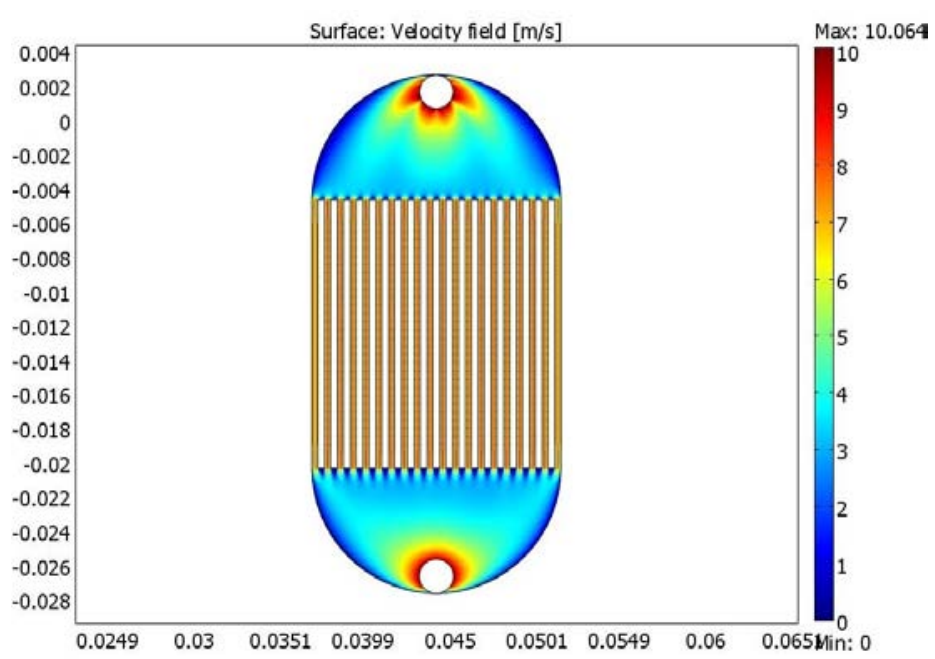

Figure 7: C-Type geometry flow distribution. 


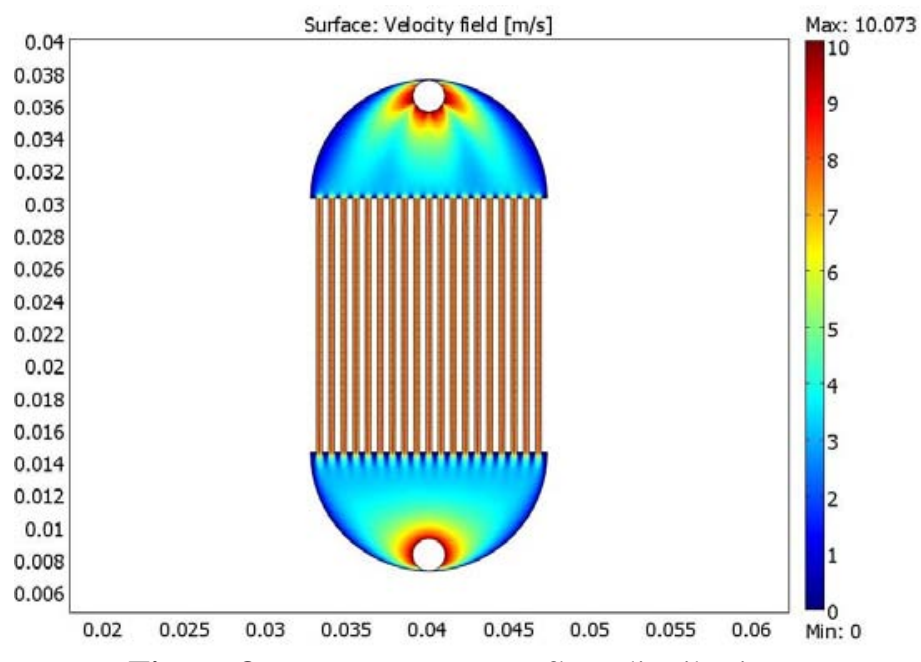

Figure 8: D-Type geometry flow distribution.

A comparison of all the geometric projects is shown in Figure 9. Thus, for the A-type geometry, the standard deviation of the average velocity was 0.11 and the maximum velocity 0.17 .

The B-type geometry shows higher deviations (0.16 and 0.23) in the average and maximum velocities, respectively. These are reasonably high, which indicates lack of homogeneity in the velocities simulated for the different channels. In fact, as shown in this Figure, the average velocity is not the same in the different channels; the deviation is bigger in areas closer to the walls.

For the C-type geometry, relatively small standard deviations were obtained; the deviation of the average velocity was 0.10 and of the maximum velocity was 0.13 . Therefore, it can be said that this geometry leads to a more homogeneous flow distribution, because there is a better homogeneity for similar inlet velocities.

In the D-type geometry, the standard deviations were even smaller, 0.007 for the average velocity and 0.008 for the maximum velocity. That indicates homogeneity in the results, as is shown in Figure 9. This flow distribution in this geometry may, therefore, be considered the most homogeneous among the four geometries studied for a velocity of $10 \mathrm{~m} / \mathrm{s}$.

With the purpose of evaluating the influence of velocity on the gas flow inside the microchannels, two additional simulations were made, one for $\mathrm{v}=3$ $\mathrm{m} / \mathrm{s}$ and another for $50 \mathrm{~m} / \mathrm{s}$. The results shown in Table 3 indicate that, for velocities lower than 10 $\mathrm{m} / \mathrm{s}$, the behavior of the gas inside the channels is more homogenous and that it worsens for higher velocities. Note that incompressibility is not found for the velocity of $50 \mathrm{~m} / \mathrm{s}$.

The results for the meshes presented in Table 4 show that the C-type geometry had the lowest degree of freedom and the lowest number of triangular elements, because it used a different size of mesh. All meshes used in the present work had values of AR larger than 0.7 over almost all the domain, with some worse elements with a lower AR of about 0.01 for the D-type project.

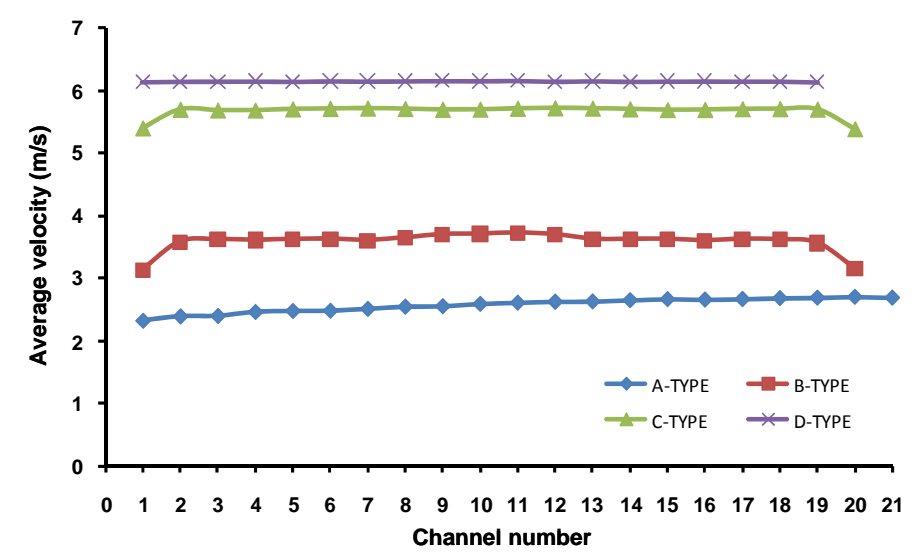

Figure 9: Average velocities for the four proposed geometries. 
Table 3: Results for D-type geometry simulations.

\begin{tabular}{|c|c|c|c|c|c|c|}
\hline Velocity (m/s) & ${ }^{1} \mathbf{v}_{\mathbf{m}}(\mathbf{m} / \mathbf{s})$ & ${ }^{2} \boldsymbol{\Sigma}$ & ${ }^{3} \mathbf{v}_{\mathbf{M a x}}(\mathbf{m} / \mathbf{s})$ & $\boldsymbol{\Sigma}$ & $\boldsymbol{R e}(\mathbf{- )}$ & ${ }^{4} \boldsymbol{\Delta P}(\mathbf{P a})$ \\
\hline $\mathrm{V}=3$ & 1.69 & 0.002 & 2.55 & 0.002 & 13.2 & 163 \\
$\mathrm{~V}=10$ & 6.15 & 0.007 & 8.81 & 0.008 & 48.3 & 1365 \\
$\mathrm{~V}=50$ & 27.92 & 0.04 & 40.24 & 0.05 & 218.8 & 25147 \\
\hline
\end{tabular}

${ }^{1} \mathbf{V}_{\mathbf{m}}$ average flow velocity; ${ }^{2} \boldsymbol{\Sigma}$ standard deviation; ${ }^{3} \mathbf{V}_{\text {Max }}$ maximum velocity; ${ }^{4} \Delta \mathbf{P}$ pressure drop.

Table 4: Mesh analysis for 2-D geometries.

\begin{tabular}{|c|c|c|c|c|}
\hline \multirow{2}{*}{ Mesh } & \multicolumn{4}{|c|}{ Types } \\
\hline & $\mathbf{A}$ & B & C & D \\
\hline Number of degrees of freedom & 839551 & 624492 & 443434 & 642707 \\
\hline Number of mesh points & 95493 & 71176 & 50810 & 50810 \\
\hline Number of triangular elements & 181024 & 134288 & 94672 & 138752 \\
\hline Size & Normal & Normal & Coarser & Normal \\
\hline Refinement method & Regular & Regular & Regular & Regular \\
\hline Minimum element quality & 0.603 & 0.613 & 0.034 & 0.0112 \\
\hline
\end{tabular}

\section{3-D Simulations}

Because the computational effort and simulation time are elevated for the 3-D simulations, we opted for the use of less refined meshes and the analysis was made based on the pressure drop and then only qualitatively because quantitative analysis did not produce very clear results.

The pressure drop was larger for simulations in 3-D than for the equivalent ones in 2-D, as can be observed in Table 5 for three different velocities. The explanation for this fact is that, in the case of the 3-D simulation, the software considers four walls for each channel, while in the 2-D simulations the geometry is treated as if each channel were a fissure between two straight, semi-infinite plates, which makes the pressure variation smaller in the latter case.

Table 5: Results for the pressure drop of projects $C$ and $D$.

\begin{tabular}{|c|c|c|c|}
\hline \multirow{2}{*}{ Geometry } & \multicolumn{3}{|c|}{$\left.{ }^{\mathrm{I}} \mathbf{\Delta P} \mathbf{( P a}\right)$} \\
\cline { 2 - 4 } $\mathrm{C}$ & ${ }^{2} \mathbf{V}=\mathbf{3} \mathbf{~ m} / \mathbf{s}$ & $\mathbf{V}=\mathbf{1 0} \mathbf{~ m} / \mathbf{s}$ & $\mathbf{V}=\mathbf{5 0} \mathbf{~ m} / \mathbf{s}$ \\
\cline { 2 - 4 } $\mathrm{D}$ & 154 & 1293 & 25025 \\
& 163 & 1365 & 25148 \\
\hline
\end{tabular}

${ }^{1} \Delta \mathbf{P}$ pressure drop; ${ }^{2} \mathbf{V}$ plate inlet velocity.

The 3-D simulations used for the qualitative analysis are presented in Figures 10 and 11 for the velocity of $10 \mathrm{~m} / \mathrm{s}$ in geometries $\mathrm{C}$ and $\mathrm{D}$, respectively. Note that the maximum velocity obtained in the D-type geometry is higher than in the C-type geometry. A qualitative evaluation of the simulations in 3-D and 2-D shows similar behavior, so the 2-D results were considered to be trustworthy, since the computational effort for the simulation in 2-D is lower compared with 3-D.

In Table 6, the mesh analysis for both 3-D geometries is presented. Note that, again, the C-type geometry showed the highest degree of freedom. Both geometries present values of AR larger than 0.7 over almost all the domain, with some elements with lower AR of about 0.0035 (C-type).

Table 6: Mesh analysis for 3-D geometries.

\begin{tabular}{|l|r|r|}
\hline \multirow{2}{*}{\multicolumn{1}{|c|}{ Mesh }} & \multicolumn{2}{|c|}{ Types } \\
\cline { 2 - 3 } & \multicolumn{1}{|c|}{ C } & \multicolumn{1}{c|}{ D } \\
\hline Number of degrees of freedom & 1465703 & 1411865 \\
Number of mesh points & 70892 & 68312 \\
Number of tetrahedral elements & 277954 & 267672 \\
Type & Normal & Normal \\
Method & Longest & Longest \\
Minimum element quality & 0.0035 & 0.0074 \\
\hline
\end{tabular}

\section{EXPERIMENTAL PROCEDURE}

\section{Micro-Heat Exchanger Construction - LTCC Technology}

The aluminum vitroceramic in the "green" state (before sinterization) enables the generation of holes, channels and hollows in a simple way up to 200 micrometers. After the individual layer process, they are laminated and a multi-layer system is obtained. When the laminated system is co-sinterized, a hard body is generated with the desired application. For the fabrication of the micro-heat exchanger plates, green ceramic $951 \mathrm{PX}$ tapes with $250 \mu \mathrm{m}$ thickness from Dupont (with a Thermal Conductivity of $3.3 \mathrm{~W} / \mathrm{m} . \mathrm{K}$ ) were used. The device construction process follows the sequence presented in Figure 12. Since this technology is based on the multilayer approach, the current project considers four stacked layers for a specific geometry. In order to stack the tapes, it was necessary to carry out different compaction tests with variable temperatures, time and pressure parameters to prevent delamination, because the channels depth is $500 \mu \mathrm{m}$ (the thickness of two tapes). The lamination process was made in a uniaxial hydraulic press with the adaptation of an electric resistance set for the thermal transfer. The geometries were projected in the CAD software and then, simulated with CFD software in order to choose the best fluid dynamics behavior. 
Slice: Velocity field $[\mathrm{m} / \mathrm{s}]$

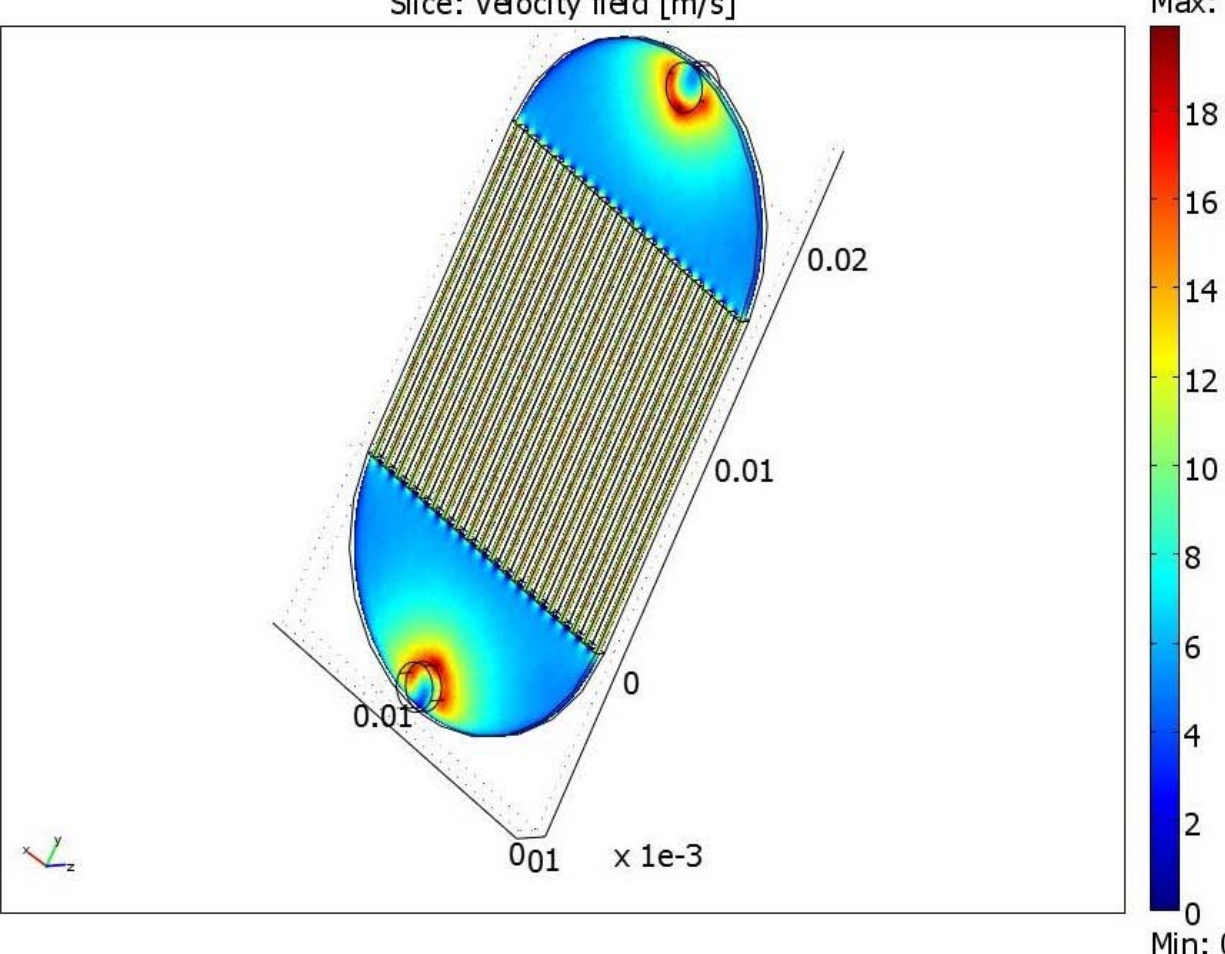

Figure 10: 3-D Simulated (C-Type) velocity distribution.

Slice: Velocity field $[\mathrm{m} / \mathrm{s}]$

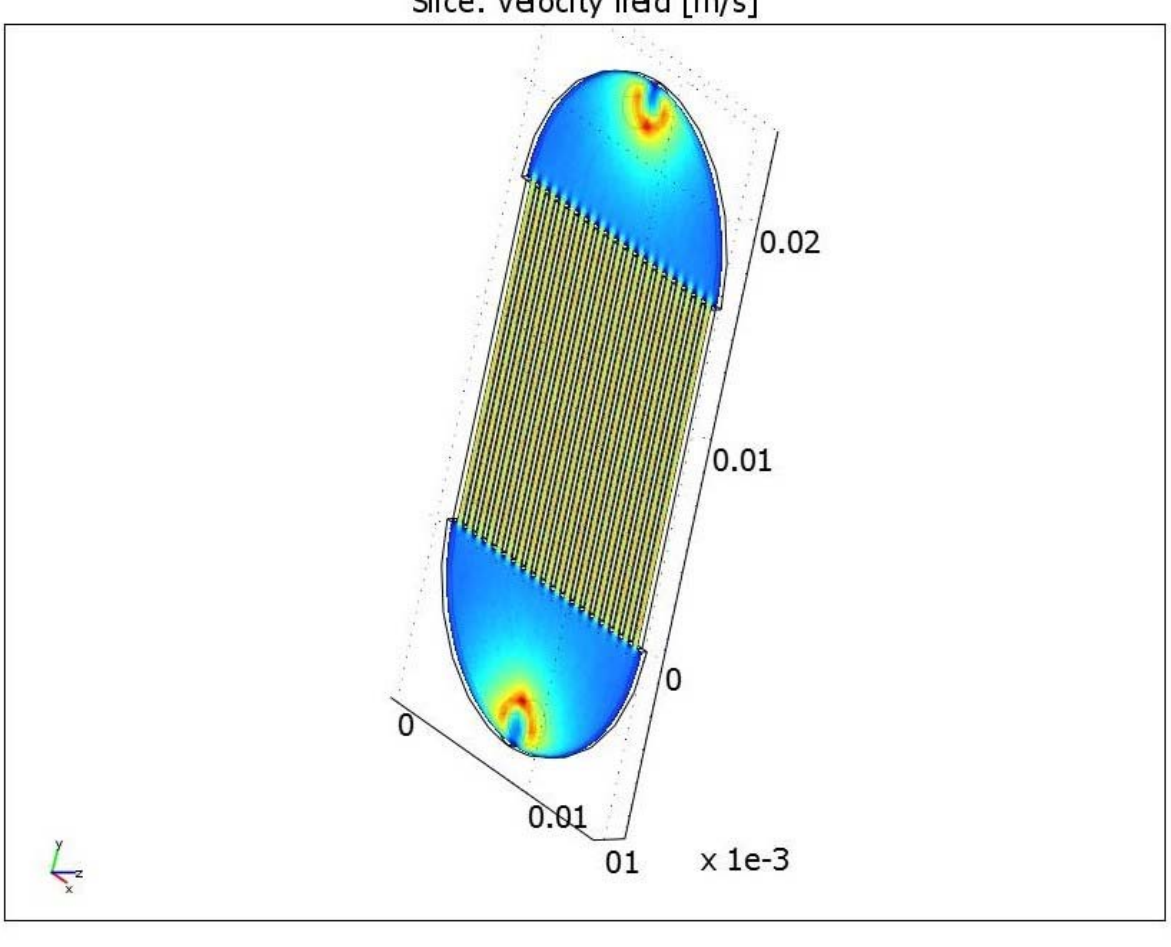

Min: 0
Max: 22.0

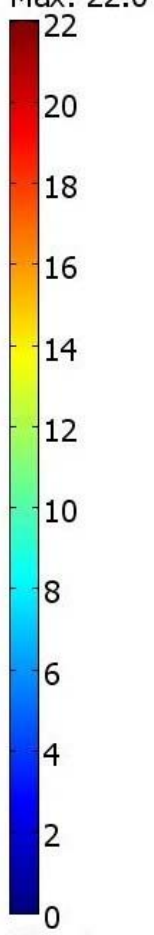

Figure 11: 3-D Simulated (D-Type) velocity distribution. 


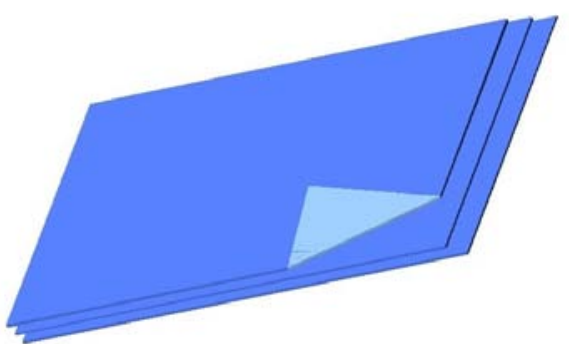

Tapes lamination

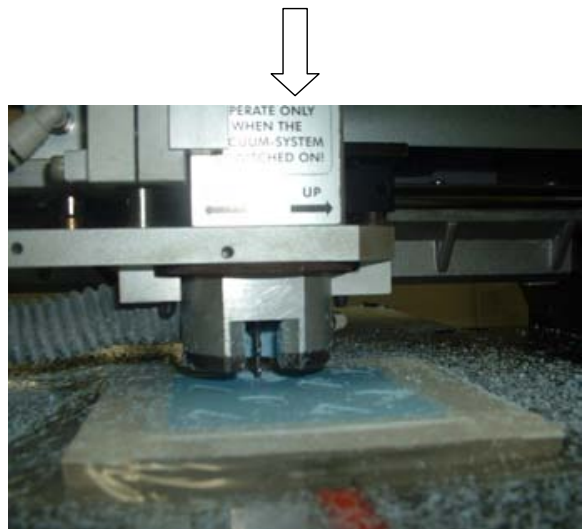

CNC machining

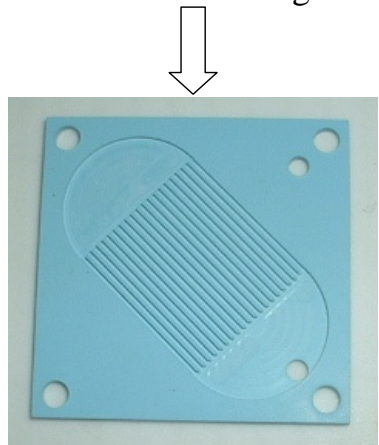

Machined green plates

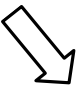

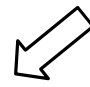
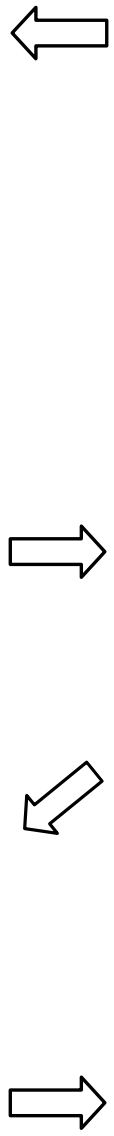

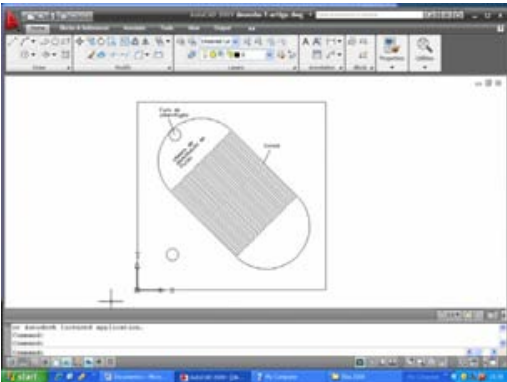

CAD design
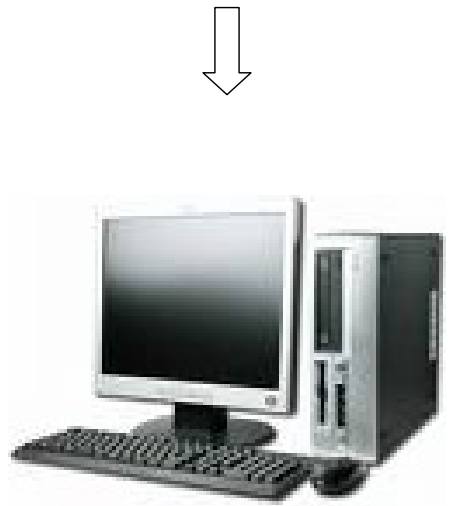

CFD

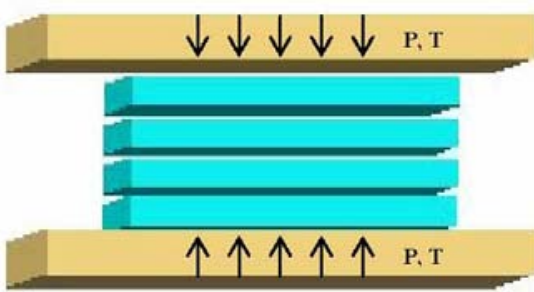

Thermo compression

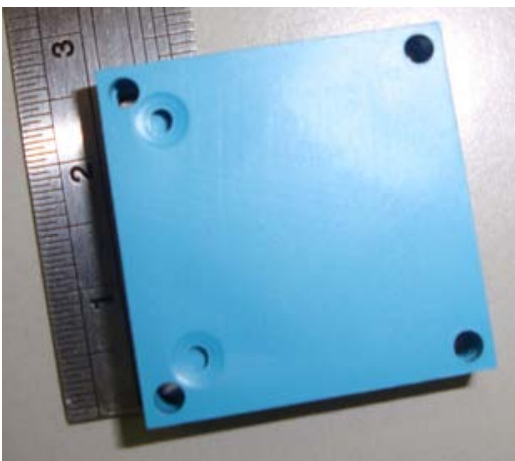

Final Device

Figure 12: Fabrication process of the micro-heat exchangers. 
The microchannel machining was made with a CNC PROTOMAT C100/HF milling cutter, which uses $400 \mu \mathrm{m}$ cutters and $2.00 \mathrm{~mm}$ drills. Then, the green ceramic plates are glued together in a crossed way with a thin layer of an organic fluid (Da Rocha et al., 2004) and they are laminated at a pressure of $1.69 \mathrm{MPa}$.

Finally, the laminated device was sintered in an air atmosphere in a furnace. The sintering process is carried out in 4 steps. At first, the temperature increases at the rate of $10^{\circ} \mathrm{C} / \mathrm{min}$ until $350^{\circ} \mathrm{C}$. Then, in the second step, the temperature is maintained at $350^{\circ} \mathrm{C}$ for 30 minutes. In the third step, the temperature is increased at $10^{\circ} \mathrm{C} / \mathrm{min}$ until $850^{\circ} \mathrm{C}$ and, in the fourth step, the final temperature maintained for 30 minutes and then decreased. In Figure 12, the sintering process graph is presented.

\section{Experimental Setup with Procedures}

The cross-flow micro-heat exchanger was initially installed in a metal housing specially projected for this experiment, but this material led to huge heat losses. In order to avoid this problem, an acrylic housing was later projected and constructed. The micro-heat exchanger was attached to the acrylic housing with Kalrez O-rings, which can also be used to avoid heat losses, as can be seen in Figure 13.

The gas flow circuits were analyzed using nitrogen gas; rotameters were employed to measure gas flow and thermocouples to measure the temperatures at each point of gas inlet and outlet in the micro-heat exchanger (see Figure 13). It was necessary to build a special system of temperature measurement adapted from commercial thermocouples, since the dimensions are extremely reduced. An electrical heater was used to heat the warm gas stream entering the exchanger up to the desired temperature.

\section{DISCUSSION}

All the processes involved in the construction were difficult to be carried out. For example, the lamination of the tapes without the appropriate temperature and pressure led to a total delamination of the channels, as shown in Figure 14(a); a sample with four plates machined with the optimal pressure and temperatures is shown in Figure 14(b).

Other problems found in the construction process were related to the assembly, lamination and sintering of the plates. In Figure 14(c), where the micro-heat exchanger was cut to evaluate the microchannels, it is possible to see that the microchannels are not bonded and there are cracks in the walls, which are not present in Figure 14(d).

The micro-heat exchangers were tested for internal and external leaks, in order to make sure they did not have small cracks that could not be identified visually. Figure 14(e) shows the broken device and Figure 14(f) shows the good micro-heat exchanger. Note the dimensions of the exchanger plates in the latter case.

Preliminary tests are currently underway for verifying the effect of different flows and configurations in the micro-heat exchanger. The results will be reported in a future communication.

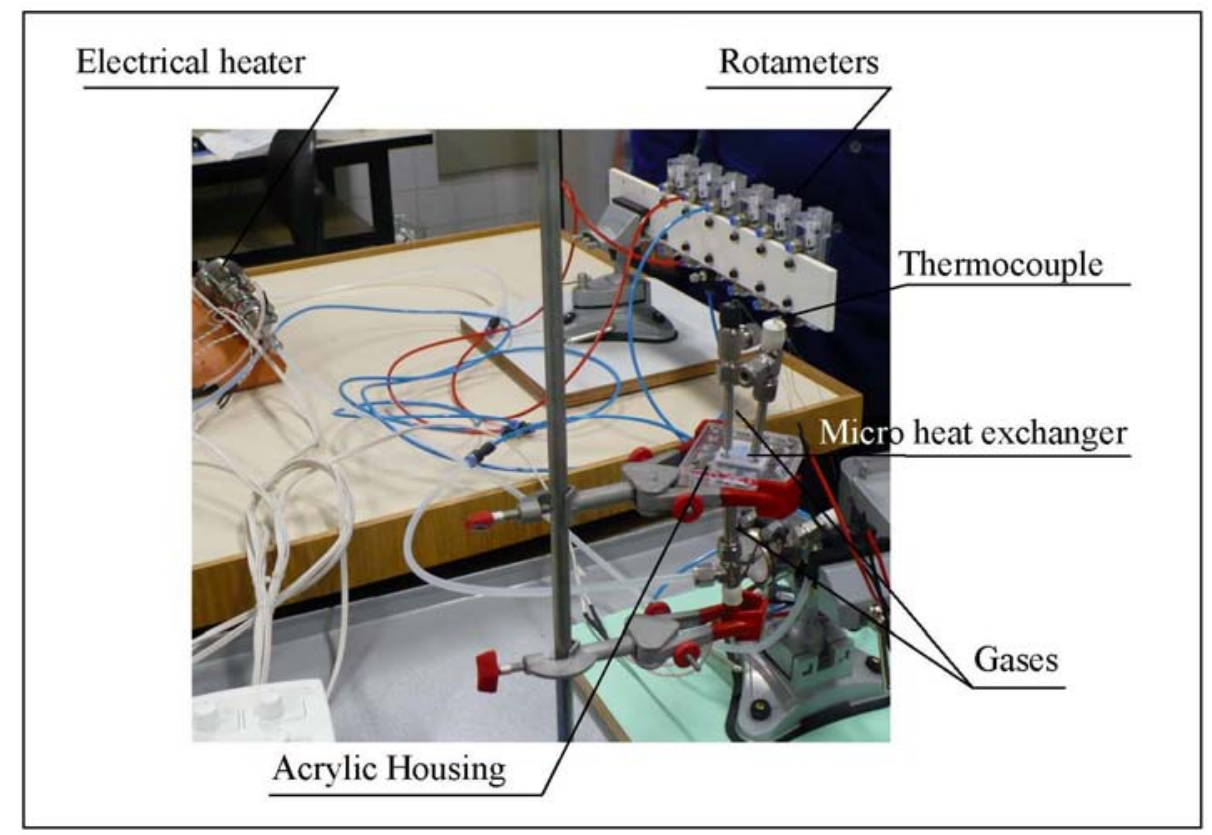

Figure 13: Experimental setup of the micro-heat exchanger. 


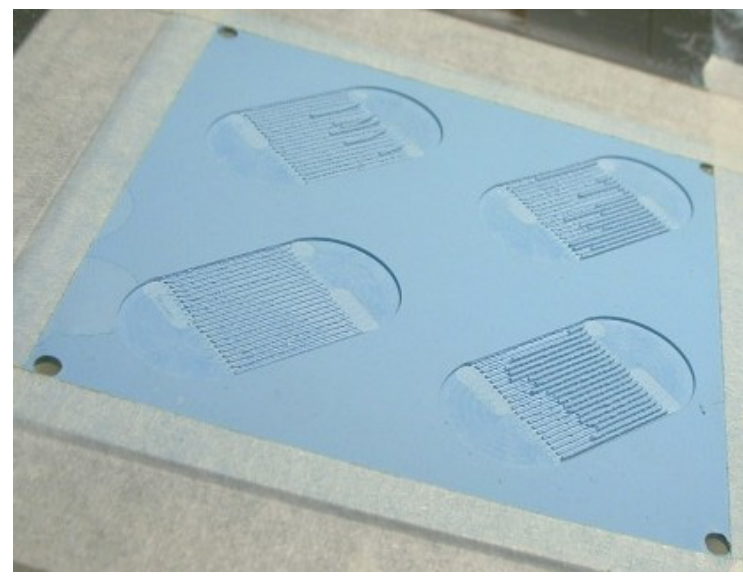

(a)

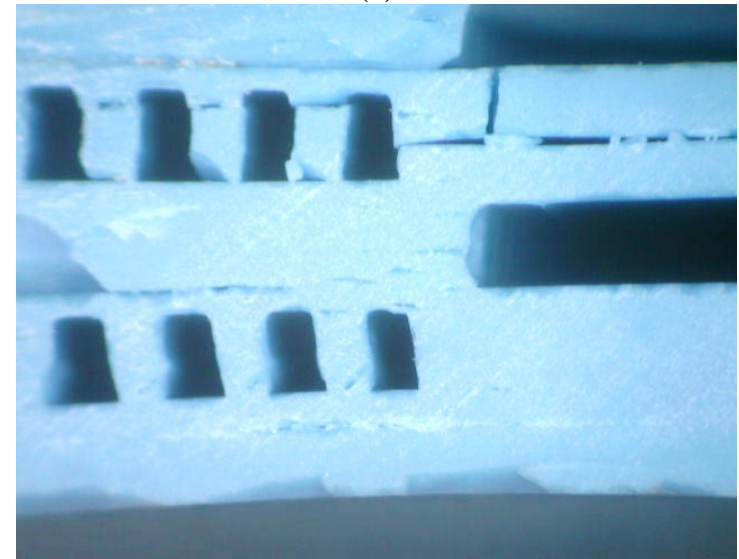

(c)

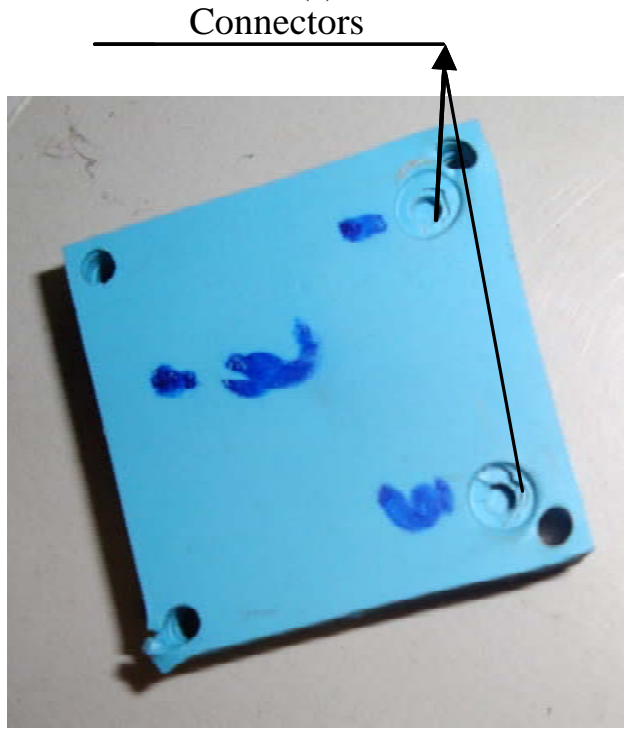

(e)

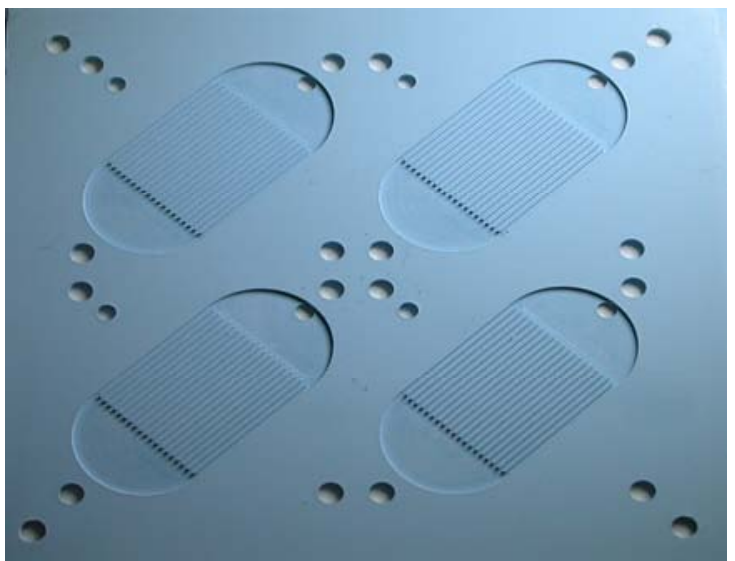

(b)

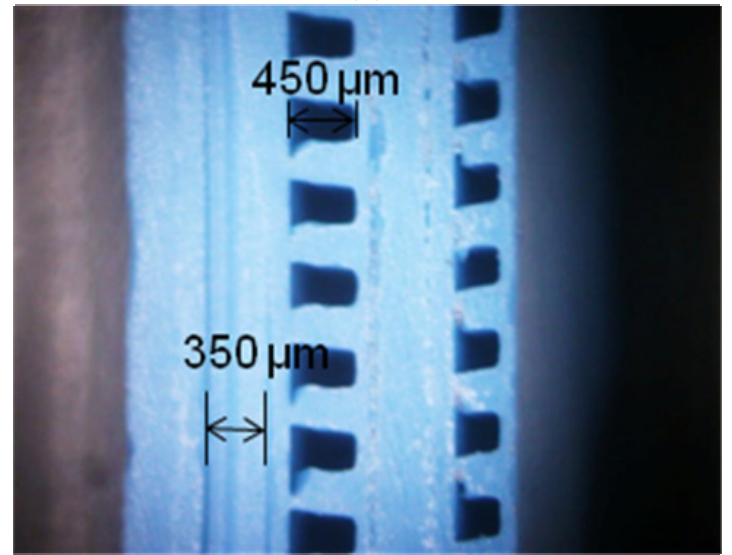

(d)

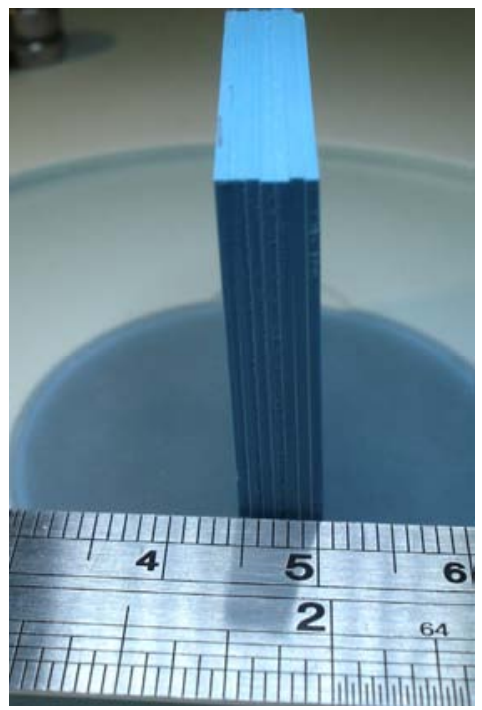

(f)

Figure 14: LTCC device Photos. 


\section{CONCLUSION}

LTCC technology is quite useful for developing novel devices to integrate non-electrical functions for microfluidics, analytical chemistry, microplasma and microreaction applications

In this work, a cross-flow multi-plate micro-heat exchanger was designed and manufactured. CFD simulations were used to study the fluid distribution between the parallel channels and the D-type geometry presented the best behavior of flow distribution when compared with the three other geometries considered.

Further modifications are ongoing in order to improve electronic instrumentation, temperature sensor measurement, flow measurement and system thermal insulation.

\section{ACKNOWLEDGEMENTS}

The financial support from CNPq-CTPetro (grant number 502637/2003-0, and individual scholarship number 383609/06-2) and FAPESP (grant number 2007/03812-5) is gratefully acknowledged.

\section{NOMENCLATURE}

\begin{tabular}{|c|c|}
\hline A & Avogadro number \\
\hline $\mathrm{D}_{\mathrm{H}}$ & Hydraulic diameter \\
\hline $\mathrm{d}_{\min }$ & $\begin{array}{l}\text { minimal characteristic } \\
\text { dimension }\end{array}$ \\
\hline g & gravitational acceleration \\
\hline h & Channel height \\
\hline Kn & Knudsen number \\
\hline $\mathrm{L}$ & Channel length \\
\hline$n$ & Channel number \\
\hline$P$ & $\begin{array}{l}\text { minimum operating } \\
\text { pressure }\end{array}$ \\
\hline $\mathrm{P}_{\mathrm{w}}$ & $\begin{array}{l}\text { wet perimeter of the } \\
\text { channel }\end{array}$ \\
\hline $\mathrm{R}$ & universal gas constant \\
\hline $\operatorname{Re}$ & Reynolds number \\
\hline rh & hollow radius \\
\hline S & Cross-sectional area \\
\hline $\mathrm{T}$ & Temperature \\
\hline u & fluid velocity \\
\hline $\mathrm{V}$ & plate inlet velocity \\
\hline $\mathrm{V}_{\mathrm{m}}$ & $\begin{array}{l}\text { average flow velocity used } \\
\text { to calculate the Reynolds }\end{array}$ \\
\hline$v_{\max }$ & maximum velocity \\
\hline $\mathrm{W}_{\mathrm{a}}$ & Channel wall width \\
\hline $\mathrm{W}_{\mathrm{c}}$ & Channel width \\
\hline
\end{tabular}

\section{Greek Letters}

$\begin{array}{llr}\Delta \mathrm{P} & \text { pressure drop } & \text { pa } \\ \mu & \text { dynamic viscosity } & \text { Pa.s } \\ \Lambda & \text { molecular mean free path } & \mathrm{M} \\ \rho & \text { density } & \mathrm{kg} / \mathrm{m}^{3} \\ \sigma & \text { molecular diameter } & \mathrm{m} \\ \Sigma & \text { standard deviation } & (-)\end{array}$

\section{REFERENCES}

Alm, B., Imke, U., Knitter, R., Schygulla, U., Zimmermann, S., Testing and simulation of ceramic micro heat exchangers. Chemical Engineering Journal, 135, (1), 179-184 (2008).

Arzamendi, G., Diéguez, P. M., Montes, M., Odriozola, J. A., Sousa-Aguiar, E. F., Gandia, L. M., Methane steam reforming in a microchannel reactor for GTL intensification: A computational fluid dynamics simulation study. Chemical Engineering Journal, 154, (1-3), 168173 (2009).

Commenge, J-M., Falk, L., Corriou, J-P., Matlosz, M., Optimal Design for flow uniformity in Microchannel Reactors. AICHE Journal, 48, No 2, 345-358 (2002).

Da Rocha, Z. M., Ibañez-Garcia, N., Oliveira, N. A., Matos, J. R., Gongora-Rubio, M. R., Low temperature and pressure lamination of LTCC tapes for meso-systems. In: IMAPS Conference and exhibition on ceramic interconnect technology, Denver (2004).

Ehrfeld, W., Hessel, V., Löwe H., Microreactors: New Technology for Modern Chemistry, WileyVCH, Germany (2000).

Gongora-Rubio, M. R., .Espinoza-Vallejos, P., SolaLaguna, L., Santiago-Aviles, J. J., Overview of Low Temperature Co-Fired Ceramics Tape Technology for Meso-System Technology (MsST). Sensors and Actuators A-Physical, 89, 222-241 (2001).

J/mol.K Griffini, G., Gavriilidis, A., Effect of microchannel Plate Design on Fluid Flow Uniformity at Low Flow Rates. Chemical Engineering Technology, 30, No. 3, 395-406 (2007).

Hessel, V., Hardt, S., Löwe, H., Chemical Micro Process Engineering: Fundamentals, Modelling and Reactions. Wiley-VCH, Germany (2004).

Ibáñez-García, N., Martinez-Cisneros, C. S., Valdés, F., Alonso, J., Green Tape ceramics. New technological approach for integrating electronics and fluidics in Trends in Analytical Chemistry, 27, No. 1, 24-33 (2008) 
Incropera, F. P., De Witt, D. P., Fundamentos de Transferência de Calor e de Massa, LTC, Brazil, (in Portuguese) (2003).

Kang, S-W., Tseng, S-C., Analysis of effectiveness and pressure drop in a micro cross-flow heat exchanger. Applied Thermal Engineering, 27, 877-885 (2007).

Kockmann, N., Transport Phenomena in Micro Process Engineering. Springer, Germany (2008).

Malecha, K., and Golonka, L. J., Microchannel fabrication process in LTCC ceramics. Microelectronics Reliability, 48, 866 -871 (2008).

Martinez-Cisneros, C. S., Ibáñez-García N., Valdés F., Alonso J., LTCC Microflow analyzers with monolithic integration of thermal control. Sensors and Actuators A-Physical, 138, 63-70 (2007).

Martinez-Cisneros, C. S., Da Rocha, Z., Ferreira, M., Valdés, F., Seabra, A., Gongora-Rubio, M., Alonso-Chamarro, J., A Monolithic Continuousflow Microanalyzer with Amperimetric Detection based on the Green Tape Technology. Analytical Chemistry, 81, 7448-7453 (2009).

Tonomura, O., Tanaka, S., Noda, M., Kano, M., Hasebe, S., Hashimoto, I., CFD-based optimal design of manifold in plate-fin microdevices. Chemical Engineering Journal, 101, 397-402 (2004). 